\title{
Multi-point temperature measuring equipment for crop environment, with some results on horizontal homogeneity in a maize crop. 1. Field results
}

\author{
C. J. Stigter ${ }^{1}$, J. Birnie and P. Jansen
}

Department of Physics and Meteorology, Agricultural University, Wageningen, the Netherlands

Accepted: 17 September 1976

Key words: micrometeorology, temperature measurement

\section{Summary}

After review of the purposes that have in the course of time been served by investigations on aerial temperature inside and just above plant stands, sensor choice, radiation protection and measured temperature profiles within a maize crop are described and discussed. Special attention is paid to the hardly explored horizontal homogeneity of temperature measured. An important conclusion that can be drawn from the results is that a growing difference with depth in the canopy between simultaneously measured extremes at a certain height is not only a matter of decreasing turbulent exchange coefficient. The inhomogeneity of soil surface conditions must be concerned as the essential initiator of such differences in the lower part of the canopy.

\section{Introduction}

Temperature measurements below, within and directly above crops have been made already for fifty years. Originally one was only interested in occurring differences between such measurements and measurements taken in the open (reviews of this early work, e.g., by Ramdas, 1946; Geiger, 1961; and Uchijima, 1974). Results for maize were published for one special day by Tamm \& Funke (1955) and for a complete growing season by Katić \& Stanojević (1964). As soon as one became interested in sources, sinks and transport mechanisms of heat and moisture within crops (e.g. Penman \& Long, 1960; Monteith, 1963; Philip, 1964; Monteith, 1973; Uchijima, 1974) temperature profiles served for calculations on within crop energy

1 Present address: University of Dar es Salaam, Department of Physics, P.O. Box 35063, Dar es Salaam, Tanzania. 
budgets and one-dimensional transfer explorations. Such an extensive preliminary investigation for maize was made by Brown \& Covey (1966).

Recently trends have developed to overcome the unguided reductional approach in plant biology by attempts to understand, by more synthesis, the ways in which the various processes are integrated to produce finally the response shown by whole plants when they are grown as a community in a natural environment (de Wit, 1970; Milthorpe \& Moorby, 1974). The set-up of crop growth simulation models forms such a trend (e.g. Paltridge, 1970; van Keulen \& Louwerse, 1974; de Wit \& Penning de Vries, 1977). In such models for example the temperature has to be quantitatively known for determination of rates of temperature dependent processes. It has to be taken preferably from a canopy climate simulation sub-model (e.g. Waggoner \& Reifsnyder, 1968).

Among other things comparison between simulated and measured temperature profiles is used in such models as a check of their validity and scope (Goudriaan \& Waggoner, 1972; Lemon et al., 1973). Sufficient field tests of models to indicate areas for research to improve our understanding and our model building are scarce (Paltridge, 1972; Paltridge et al., 1972; Shawcroft et al., 1974). Therefore an intensive field test of a micrometeorological simulation model was undertaken (Stigter, 1972, 1974; Goudriaan, 1977; Stigter et al., 1977). The choice of maize (Zea mays) was made because of its growing importance and its ability to serve as a first model evaluation crop (Brown \& Covey, 1966; Goudriaan \& Waggoner, 1972; Lemon et al., 1973; Shawcroft et al., 1974; Goudriaan, 1977).

The measuring sites have been described separately with the details necessary (Stigter \& Lammers, 1974; Stigter et al., 1976). In this paper we deal with the measurement of temperature profiles, below, within and above a maize crop, used for the mentioned evaluation of the micrometeorological simulation model. We will be concerned in this first part with the choice and use of the sensors and some field results obtained. In relation to these results emphasis is laid on a first evaluation made of the hardly explored horizontal homogeneity within the crop. A second paper (Birnie et al., in prep.) will deal with calibration of the sensors and choice, adaptation and field use of scanning and data logging equipment.

\section{Thermometers used}

\section{Choice of the sensor and related measures}

The choice of the temperature sensor for temperature measurements within a crop depends on special requirements to be met. Neither may radiation directly or indirectly influence the signal nor may one disturb the natural temperature profile inside the canopy. The latter becomes more serious as soon as natural ventilation and turbulent intensity become lower, as is mostly the case deeper in the canopy.

As we wanted to measure the air temperature profile also very near to the soil surface within the crop $(10,5$ and $2 \mathrm{~cm}$ ) we decided to use unaspirated sensors throughout the crop environment. For not extremely thin thermocouples as well as for other sensors radiation protection is necessary in that case (e.g. Tanner, 1963; Platt \& Griffith, 1964; Long, 1968; Perrier, 1970; Vaughan \& Sakamoto, 1971). 
Our final decision to use platinum resistance Degussa P4 thermometers was based on three facts:

1. With their water proof protection (cf. Long, 1968) they are still small but large enough to have a sensor with a time constant in the order of half a minute in a $2 \mathrm{~m} / \mathrm{s}$ turbulent wind speed; this makes the scanning problem less difficult (Stigter et al., 1976);

2. No problems with zero references do occur in the field;

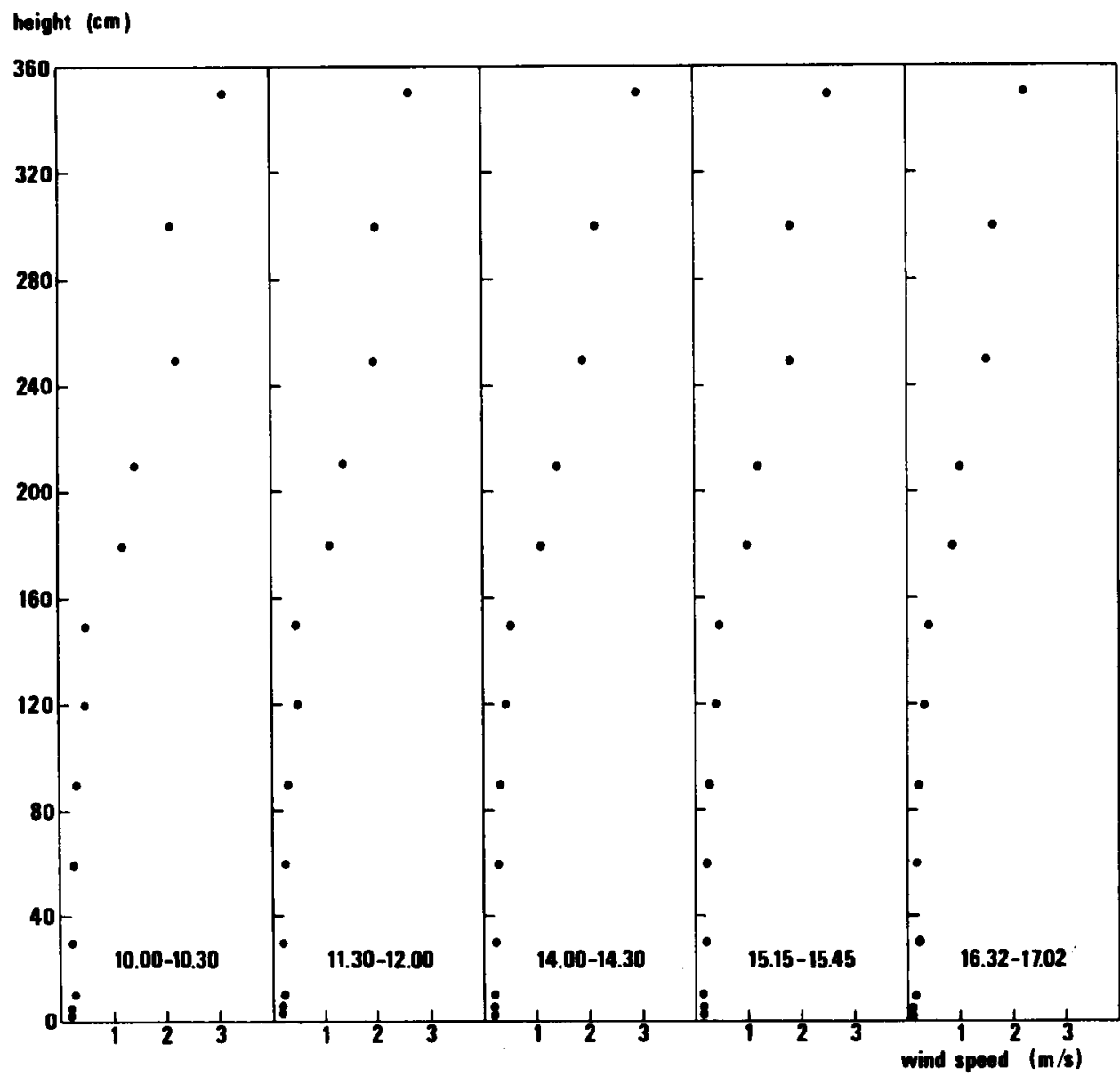

Fig. 1. Representative air movement profiles on 14 August 1973. Measurements were made with heated white sphere anemometers (Stigter et al., 1976). The shape of the curve directly below and above the top of the crop is not due to measuring errors as could be assessed by interchanging instruments, but due to the fact that all wind components are measured and turbulence intensities are different. Measuring accuracies are: $\pm 0.05 \mathrm{~m} / \mathrm{s}$ below $0.50 \mathrm{~m} / \mathrm{s}$; $\pm 0.10 \mathrm{~m} / \mathrm{s}$ between 0.50 and $1.00 \mathrm{~m} / \mathrm{s} ; \pm 0.20 \mathrm{~m} / \mathrm{s}$ between 1.00 and $2.00 \mathrm{~m} / \mathrm{s} ; \pm 10 \%$ above $2.00 \mathrm{~m} / \mathrm{s}$. 
3. Excellent results have been obtained with this kind of somewhat integrating thermometers inside the soil (e.g. Tanner, 1963).

So we could use for our soil profiles the same measuring and scanning equipment as for our air temperature profiles.

As we were interested in data on horizontal homogeneity within the crop, more complicated radiation compensation equipment was not tried (e.g. Rodskjer, 1975). In the almost isotropically sown but still relatively open (in comparison with for example a normal wheat stand) maize crop, air movement dropped on the average below $1 \mathrm{~m} / \mathrm{s}$ at a height of between $1.50 \mathrm{~m}$ and $2 \mathrm{~m}$ (for a $2.40 \mathrm{~m}$ crop). It dropped below $0.5 \mathrm{~m} / \mathrm{s}$ at an average height between $1 \mathrm{~m}$ and $1.50 \mathrm{~m}$ but was even at $2 \mathrm{~cm}$ above the soil surface always between 0.10 and $0.20 \mathrm{~m} / \mathrm{s}$ (Fig. 1) at the average.

The above means that measuring true air temperature during the day, above and inside the maize canopy downwards till very close to the ground, can be troubled in three ways:

1. The necessary radiation protection screens may hamper the natural ventilation, which is however sufficient if undisturbed;

2. The radiation protection screens may influence directly the temperature of the air to be measured by air contact with screen parts of a higher temperature;



Fig. 2. Sensors under radiation protection screens, relatively close to the soil surface. The photograph was made at the end of August, between $17 \mathrm{~h} 00$ and $18 \mathrm{~h} 00$, with a solar altitude of about $15^{\circ}$ (Photograph J. van den Brink). 
3. The screens may modify the microclimate within the crop, which may indirectly influence air temperature at a certain level.

\section{Radiation protection}

Point 1 mentioned above makes it necessary to design a relatively open radiation protection screen. Point 2 forces us to have screen surface temperatures as low as possible and geometrically spaced in a way that air warmed above ambient temperature by touching a part of the screen surface does not directly flow across the sensor. Point 3, playing a role especially near the soil surface, limits only the dimensions of the screen as long as Points 2 and 3 are met and the 'screen area index' is negligible.

The solutions which were chosen can be observed on Fig. 2. At the highest level shown there $(60 \mathrm{~cm})$ three shields can be distinguished. The left one is a single one used above the psychrometers (Stigter \& Welgraven, 1976). The middle and the right one are double shields with a $20 \mathrm{~cm} \times 20 \mathrm{~cm}$ upper part and a $10 \mathrm{~cm} \times 10 \mathrm{~cm}$ lower part. At the $30 \mathrm{~cm}$ level, left and right, also two of these shields are visible. They were used from $30 \mathrm{~cm}$ upwards.

Both outer sides are aluminized Mylar surfaces on low density Tempex, aluminized Mylar having been shown to yield relatively the lowest surface temperature in comparison to other reflecting materials under these conditions (Fuchs \& Tanner, 1965). The Tempex layers, 1 to $2 \mathrm{~cm}$ thick, are attached to aluminium bases, hold together with a $2 \mathrm{~cm}$ air split between their nearest points. These bases are painted dully white, forming a diffusely reflecting inner side, facing the thermometer with its white outer side. To prevent, lower in the canopy, the building up of air pockets of higher or lower temperature below a one side protection shield or between the two shield parts, and to enhance accessibility of the thermometers by canopy air flow, upper and lower inner sides are shaped with small angles (about $10^{\circ}$ ) sloping away from the thermometers or psychrometers (Fig. 2).

Results of energy balance calculations, taking into account that as soon as ventilation speeds become lower deeper in the canopy also the radiation load on the Mylar surfaces becomes lower and using the low thermal conductivity of Tempex, are in agreement with earlier experiences that this kind of shields yield very good results under our conditions (Tanner, 1963). At the heights of 10,5 and $2 \mathrm{~cm}$ above the surface reflection has become so low (Idso \& de Wit, 1970) that the lower protection part can be abandoned. Moreover at these heights $10 \times 10 \mathrm{~cm}$ screens were preferred. This is not much more than the middle part of a well developed maize leaf, which means that even for a measurement at $2 \mathrm{~cm}$ the climate near the soil surface under the remaining part of our screen is modified in a way approaching a natural one, given the ventilation measured.

Of course the choice of the double screen in our form is a compromise in relation to the fact that the sun is able to strike the inner side of the lower protection part at a sun altitude of somewhat less than 30 degrees (See Fig. 2 at $30 \mathrm{~cm}$ height, left part of the photograph). This is the situation at our latitude, during measuring months from May until August included, before ultimately eight o'clock and after four o'clock in the most unfavourable case (Meteorological Office, 1969). However, the 
area potentially touched by direct radiation becomes only appreciable at the time that within the crop a dense layer of vegetation everywhere prohibits most radiation, under low angle, to reach the screens. Directly below and above the top of the canopy, wind speed is such that temperature rise of the touched white surfaces will be small at that time of the day and moreover wind direction must be such that the air reaches the thermometer after having crossed a radiated area. Measurements with three screens at $120^{\circ}$ azimuth difference did reveal that influences under such conditions could be neglected.

Although testing of the screens under extreme field conditions is difficult because of the lack of an accurate standard, we tried out a comparison with a horizontal Assmann, whose entree ducts were again shielded by a single protection screen. Although problems of suction sampling (e.g. Rodskjer, 1975) may have played a role in variability, the fact that the Assmann indicated temperature was, on the average in 6 sampled 10 minutes periods, $0.05^{\circ} \mathrm{C}$ higher than the mean indications of two of our fully protected thermometers, contributed to our confidence put in this type of screen. During these experiments a high radiation load was received above a $40 \mathrm{~cm}$ maize crop with a low air speed of below $1 \mathrm{~m} / \mathrm{s}$ on the average at the measuring height of $50 \mathrm{~cm}$.

We have dealt at length with the radiation protection problem to indicate that

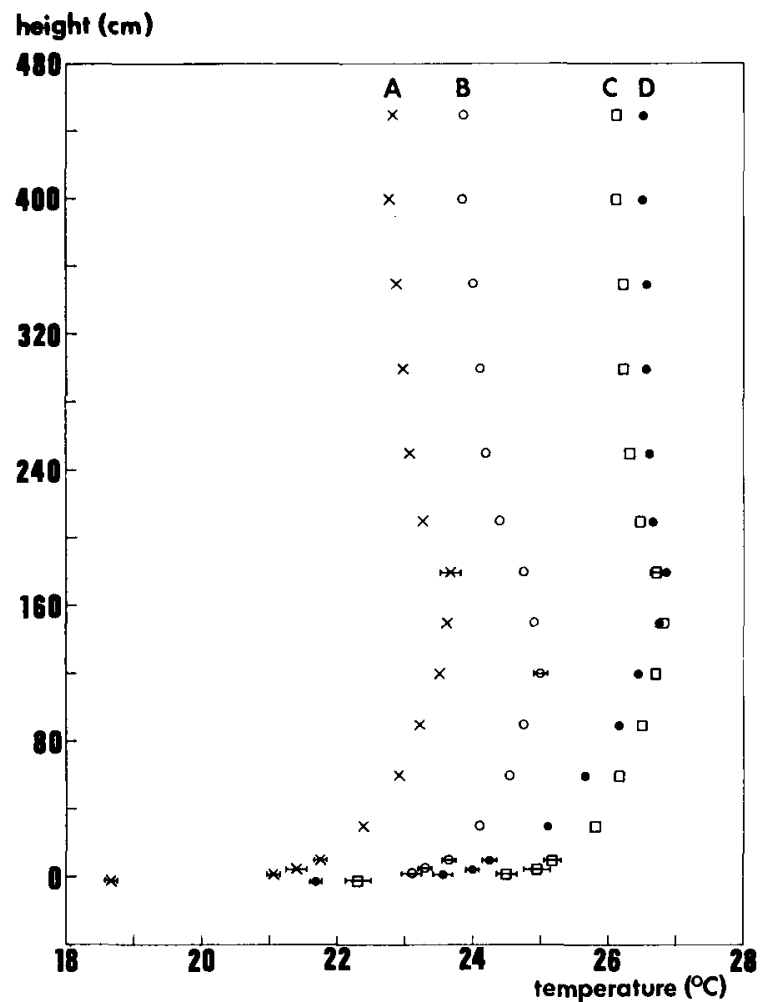

Fig. 3. Representative air temperature profiles (with the temperature at $-2 \mathrm{~cm}$ added) on 14 August 1973 for a wet soil surface.

A: $10.00-10.30 ;$ B: $11.30-12.00$; C: $14.00-14.30 ;$ D: $16.32-17.02$. If accuracies are not designed they are $\pm 0.05^{\circ} \mathrm{C}$, with the exception of B $(-2 \mathrm{~cm}): 21.65 \pm 0.6^{\circ} \mathrm{C}$. 
results on horizontal homogeneity within the crop can indeed be interpreted as differences in air temperature proper.

\section{Results and discussion}

\section{Temperature profiles}

Typical results for the temperature profiles measured are given in Fig. 3 and Fig. 4. As the air in the crop is warmed by contact with plant parts, the maximum air temperature under daylight in the crop is to be expected in a region where the leaf density increases under still high radiation intensities (e.g. Kreeb, 1974; Schwerdtfeger et al., 1975). This maximum is indeed a general tendency of temperature profiles within crops (Monteith, 1973; Landsberg, 1975).

Water supply in our experiments was never limiting evaporation (Stigter, 1974) but stress conditions may in general influence the position of the maximum air temperature within the crop (Monteith, 1973). In this context midday closure of stomata also heavily influences temperature profiles (Begg et al., 1964). Density and struc-

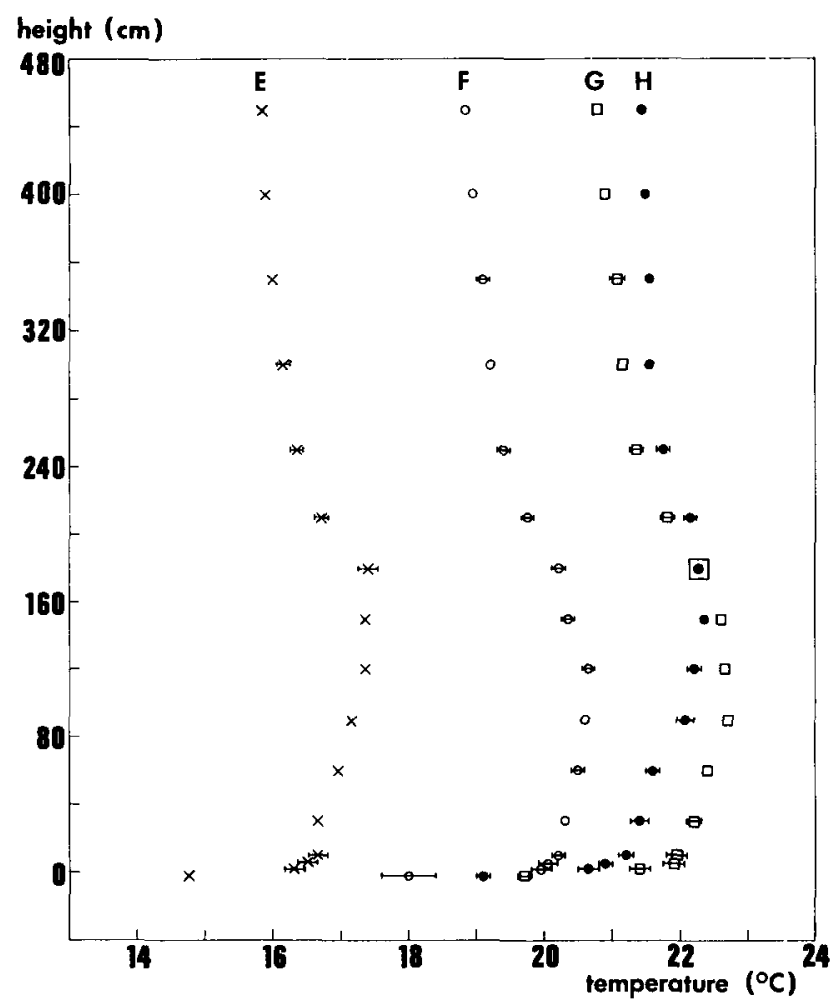

Fig. 4. Representative air temperature profiles (with the temperature at $-2 \mathrm{~cm}$ added) on 23 August 1973 for a dry soil surface. E: 9.45 - 10.15; F: 11.41 - 12.11; G: 13.50 - 14.20; H: 16.09 . 16.39. If accuracies are not designed they are $\pm 0.05^{\circ} \mathrm{C}$. 
ture of the crop of course also play their part in determination of a maximum air temperature, which may even completely disappear for a (wide) row crop (e.g. Penman \& Long, 1960; Owonubi et al., 1975). The moisture status at and near the soil surface influences soil surface temperature and soil temperature profiles and by the way the air profile near the surface (e.g. Owonubi et al., 1975).

The place of our maximum is in accordance with for example the results of Brown \& Covey (1966) for maize. Differences with the results of Shawcroft et al. (1974) for maize must be due to reported stress conditions in their crop and soil temperature and moisture conditions.

In Fig. 3 and Fig. 4 we have given four typical profiles from series of 10 and 11 half-hour profiles, respectively. Both days had clear skies and a high short-wave radiation density above the crop (Stigter \& Lammers, 1974). Because of the fine structure of the profiles it can be observed that the maxima tend to be somewhat higher in the crop in the early morning and the late afternoon, depending on the direction of the sun rays. Most radiation is absorbed higher in the crop at lower sun angle. It is also observed that average air temperatures near the soil surface are higher for the dryer soil, if compared with the temperature above the crop. Maxima for the crop above the dryer soil are also somewhat more pronounced, if again compared with above crop temperature.

Characteristic are the high differences in temperature that come into existence between average temperatures observed $2 \mathrm{~cm}$ above and $2 \mathrm{~cm}$ below soil surface, even below such a high and closed crop as matured maize. Gradients inside the soil do appear to be of the same order of magnitude for dry and for wet surface conditions (Table 1), what is in accordance with the observation that only the surface was dry but the soil was wet directly below a very superficial soil layer.

\section{Horizontal homogeneity within the crop}

By taking profiles within and above the crop and using them in a microclimate simulation model as mentioned, one makes essentially use of a one-dimensional transport theory. The assumptions underlying this theory can be challenged for quite a series of circumstances that are of agricultural interest (Penman \& Long, 1960; Byrne et al., 1971; Byrne \& Rose, 1972). We have therefore paid preliminary at-

Table. 1. Temperatures within the soil below a maize crop, to be compared with air temperature curves A up to $\mathrm{H}$ included of Fig. 3 and Fig. 4.

\begin{tabular}{lllll}
\hline Depth (cm) & A & B & C & D \\
-2 & & & & \\
-5 & $18.65 \pm 0.1$ & $21.65 \pm 0.6$ & $22.30 \pm 0.2$ & $21.70 \pm 0.1$ \\
-10 & $16.45 \pm 0.05$ & $19.05 \pm 0.15$ & $20.60 \pm 0.2$ & $20.80 \pm 0.1$ \\
\hline Depth (cm) & E & $17.30 \pm 0.1$ & $18.95 \pm 0.1$ & $19.70 \pm 0.2$ \\
\hline 2 & F & G & H \\
$-5 \times 1$ & $14.75 \pm 0.05$ & $18.00 \pm 0.4$ & $19.70 \pm 0.1$ & $19.10 \pm 0.1$ \\
-10 & $13.95 \pm 0.1$ & $16.20 \pm 0.05$ & $17.90 \pm 0.2$ & $18.20 \pm 0.2$ \\
\hline
\end{tabular}




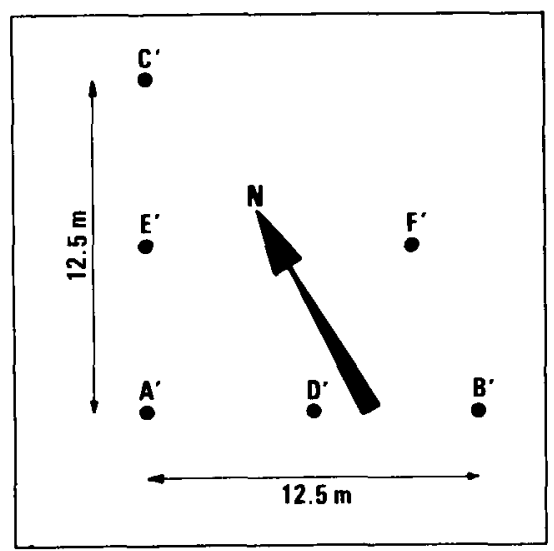

Fig. 5. Lay out of masts in the experimental maize plot. Distribution of thermometers as in Table 2. Distance between masts $\mathrm{B}^{\prime}$ and $\mathrm{C}^{\prime}$ is $17.5 \mathrm{~m}$.

tention to one of those assumptions, the horizontal homogeneity of the temperature profile. All these measurements took place in an area for which fetch influence could be excluded on wind as well as on temperature and humidity profiles above the crop (Dyer, 1968; Bottemanne \& Reitsma, 1973).

Our masts and sensors were distributed through the experimental crop part as given in Fig. 5 and Table 2. The values in Fig. 3 and Fig. 4 are averages of the measurements distributed as pictured here.

The scale of the experiment on horizontal homogeneity was drawn after the only extensive results to be found in the literature, those of Penman \& Long (1960) in a wheat crop. They found differences for four-hour averages in the order of $1{ }^{\circ} \mathrm{C}$ at

Table 2. Distribution of thermometers after place, throughout the crop (cf. Fig. 5).

\begin{tabular}{|c|c|c|c|c|c|c|c|c|}
\hline Height (m) & Mast & $\mathrm{A}^{\prime}$ & $\mathrm{B}^{\prime}$ & $\mathrm{C}^{\prime}$ & $D^{\prime}$ & $\mathbf{E}^{\prime}$ & $F^{\prime}$ & Total \\
\hline 4.50 & & & & & 3 & & & 3 \\
\hline 4.00 & & & & & 3 & & & 3 \\
\hline 3.50 & & 2 & 2 & 1 & & & & 5 \\
\hline 3.00 & & 2 & 2 & 1 & & & & 5 \\
\hline 2.50 & & 2 & 2 & 1 & & & & 5 \\
\hline 2.10 & & 2 & 2 & 1 & & & & 5 \\
\hline 1.80 & & 2 & 2 & 1 & & & & 5 \\
\hline 1.50 & & 2 & 2 & 1 & & & & 5 \\
\hline 1.20 & & 2 & 2 & 1 & & & & 5 \\
\hline 0.90 & & 2 & 2 & 1 & & & & 5 \\
\hline 0.60 & & 2 & 2 & 1 & & 2 & & 7 \\
\hline 0.30 & & 2 & 2 & 1 & 1 & 2 & 1 & 9 \\
\hline 0.10 & & & & & 1 & 2 & 1 & 4 \\
\hline 0.05 & & & & & 1 & 2 & 1 & 4 \\
\hline 0.02 & & & & & 1 & 2 & 1 & 4 \\
\hline-0.02 & & & & & & & & 5 \\
\hline-0.05 & & & & & & & & 5 \\
\hline-0.10 & & & & & & & & 5 \\
\hline
\end{tabular}


Table 3. Examples of half-hour mean temperatures within and above a maize crop in ${ }^{\circ} \mathrm{C}$, measured at different masts as pictured in Fig. 5 and for the periods as given in Fig. 3 and Fig. 4. Profiles are only partially reproduced in this table.

\begin{tabular}{|c|c|c|c|c|c|c|c|c|c|}
\hline $\begin{array}{l}\text { Height } \\
\text { (m) }\end{array}$ & & A & B & $\mathrm{C}$ & D & $\mathrm{E}$ & $\mathbf{F}$ & G & $\mathbf{H}$ \\
\hline \multirow[t]{3}{*}{4.50} & $\mathrm{D}^{\prime}$ & 22.75 & 23.80 & 26.05 & 26.40 & 15.90 & 18.90 & 20.90 & 21.50 \\
\hline & $\mathrm{D}^{\prime}$ & 22.75 & 23.85 & 26.10 & 26.50 & 15.70 & 18.80 & 20.70 & 21.35 \\
\hline & $\mathrm{D}^{\prime}$ & 22.85 & 23.85 & 26.15 & 26.60 & 15.90 & 18.80 & 20.75 & 21.45 \\
\hline \multirow[t]{5}{*}{3.00} & $\mathbf{A}^{\prime}$ & 22.95 & 24.05 & 26.25 & 26.60 & 16.10 & 19.10 & 21.15 & 21.65 \\
\hline & $\mathbf{A}^{\prime}$ & 22.85 & 24.00 & 26.15 & 26.60 & 16.00 & 19.10 & 21.05 & 21.55 \\
\hline & $C^{\prime}$ & 22.90 & 24.05 & 26.15 & 26.45 & 16.05 & 19.15 & 21.25 & 21.45 \\
\hline & $\mathbf{B}^{\prime}$ & 22.90 & 24.05 & 26.15 & 26.50 & 16.10 & 19.15 & 21.00 & 21.55 \\
\hline & $\mathbf{B}^{\prime}$ & 23.15 & 24.20 & 26.30 & 26.55 & 16.45 & 19.40 & 21.30 & 21.55 \\
\hline \multirow[t]{5}{*}{2.10} & $\mathbf{A}^{\prime}$ & 23.40 & 24.60 & 26.50 & 26.65 & 17.00 & 19.95 & 22.00 & 22.10 \\
\hline & $\mathbf{A}^{\prime}$ & 23.15 & 24.35 & 26.40 & 26.60 & 16.50 & 19.50 & 21.60 & 22.00 \\
\hline & $C^{\prime}$ & 23.25 & 24.35 & 26.35 & 26.65 & 16.75 & 19.75 & 21.85 & 22.35 \\
\hline & $\mathbf{B}^{\prime}$ & 23.20 & 24.45 & 26.45 & 26.75 & - & - & 21.70 & 21.90 \\
\hline & $\mathbf{B}^{\prime}$ & 23.15 & 24.35 & 26.50 & 26.70 & 16.65 & 19.70 & 21.95 & 22.35 \\
\hline \multirow[t]{5}{*}{1.20} & $A^{\prime}$ & 23.70 & 25.30 & 26.65 & 26.40 & 17.50 & 20.80 & 22.55 & 21.95 \\
\hline & $\mathbf{A}^{\prime}$ & 23.35 & 24.95 & 26.80 & 26.45 & 17.20 & 20.75 & 22.80 & 22.30 \\
\hline & $C^{\prime}$ & 23.75 & 25.25 & 26.70 & 26.30 & 17.45 & 20.75 & 22.60 & 21.90 \\
\hline & $\mathbf{B}^{\prime}$ & 23.30 & 24.70 & 26.65 & 26.55 & 17.25 & 20.50 & 22.60 & 22.35 \\
\hline & $\mathbf{B}^{\prime}$ & 23.40 & 24.75 & 26.75 & 26.65 & 17.30 & 20.60 & 22.80 & 22.45 \\
\hline \multirow[t]{9}{*}{0.30} & $\mathbf{A}^{\prime}$ & 22.50 & 24.30 & 25.95 & 25.15 & 16.70 & 20.45 & 22.55 & 21.45 \\
\hline & $\mathbf{A}^{\prime}$ & 22.35 & 24.05 & 25.65 & 25.10 & 16.70 & 20.25 & 22.15 & 21.45 \\
\hline & $\mathrm{C}^{\prime}$ & 22.55 & 24.20 & 25.75 & 25.05 & 16.65 & 20.35 & 22.00 & 21.20 \\
\hline & $\mathbf{B}^{\prime}$ & 22.35 & 24.00 & 25.80 & 25.35 & 16.65 & 20.15 & 22.15 & 21.55 \\
\hline & $\mathbf{B}^{\prime}$ & 22.35 & 24.00 & 26.10 & 25.35 & 16.75 & 20.20 & 22.60 & 21.70 \\
\hline & $E^{\prime}$ & 22.25 & 24.00 & 25.65 & 24.95 & 16.70 & 20.30 & 22.15 & 21.30 \\
\hline & $E^{\prime}$ & 22.15 & 23.90 & 25.60 & 24.85 & 16.60 & 20.20 & 22.05 & 21.25 \\
\hline & $F^{\prime}$ & 22.25 & 24.15 & 25.60 & 24.75 & 16.60 & 20.10 & 21.90 & 21.25 \\
\hline & $\mathrm{D}^{\prime}$ & 22.50 & 24.20 & 26.15 & 25.15 & 16.80 & 20.45 & 22.45 & 21.50 \\
\hline \multirow[t]{4}{*}{0.02} & $\mathrm{E}^{\prime}$ & 20.90 & 22.60 & 24.10 & 23.40 & 16.35 & 19.85 & 21.20 & 20.55 \\
\hline & $\mathbf{E}^{\prime}$ & 21.20 & 22.90 & 24.30 & 23.50 & 16.55 & 20.10 & 21.35 & 20.55 \\
\hline & $F^{\prime}$ & 20.80 & 23.20 & 24.40 & 23.30 & 15.90 & 19.45 & 20.85 & 20.15 \\
\hline & $\mathbf{D}^{\prime}$ & 21.25 & 23.60 & 25.20 & 24.05 & 16.50 & 20.45 & 22.15 & 21.35 \\
\hline
\end{tabular}

places $8 \mathrm{~m}$ apart and outside advective influences. They even suggest that such differences may occur within the wheat crop at places something as one metre apart. In our experiments horizontal distances between thermometers at one mast are between 60 and $70 \mathrm{~cm}$ and between thermometers at different masts from a minimum in the order of $5 \mathrm{~m}$ to a maximum of almost $20 \mathrm{~m}$.

One of the first conclusions that may be drawn from the two measuring days in 1972 and the four measuring days in 1973 is that temperature differences observed in the horizontal at a certain height are not higher between masts than between two 
measurements at the same mast. Examples may be observed in Table 3 where we have collected the temperatures from which Fig. 3 and 4 have been drawn, so from 8 of the 21 profiles of the two days concerned. The statement applies from $30 \mathrm{~cm}$ upwards.

To appreciate horizontal differences one has to take into account that for assessment of the maximum differences due to natural variation, in which we are interested, we have to take two other sources into consideration. Firstly, due to calibration uncertainties $0.1{ }^{\circ} \mathrm{C}$ difference may be measured between points of equal temperature. Secondly, errors due to the necessary time sampling method applied may result at maximum at again an estimated $0.1{ }^{\circ} \mathrm{C}$ difference (Stigter et al., 1976).

With this in mind we found for the four measuring days of 1973 the maximum differences in the horizontal, over the $200 \mathrm{~m}^{2}$ area sampled, due to natural inhomogeneities, as collected in Table 4 . For example, the difference of $0.6{ }^{\circ} \mathrm{C}$ at $1.20 \mathrm{~m}$ for column $\mathrm{B}$ in Table 3 is near the maximum of $0.7^{\circ} \mathrm{C}$ observed for that height (the latter leading to an estimation of $0.5^{\circ} \mathrm{C}$ in Table 4 for the maximum difference due to horizontal inhomogeneity from natural variation).

Above the crop differences are least but sometimes identification of relative 'warm' places was possible horizontally, but not vertically in the profile. No reason could be established for occurrence of this phenomenon, but stand inhomogeneities and resulting complex three-dimensional streaming patterns over the crop may be involved. It is only very near to the soil surface that, not without troubles, really different temperature and humidity (Stigter, 1976) profiles at one and the same time can be more or less identified and that any regularity in the course of such profiles over the day can be distinguished. We have given some examples for temperature in Table 5.

With proper care it may be suggested that the maximum in horizontal temperature difference at $1.80 \mathrm{~m}$ (Table 4) is due to a maximum increase in leaf area density just above the height where the crop becomes 'closed', and a comparable decrease in turbulent mixing. A growing maximum difference with depth lower in the canopy is in agreement with the trend observed by Penman \& Long (1960) in wheat. They suggest that this is due to less horizontal mixing deeper in the canopy. It follows

Table 4. Observed maximum horizontal temperature differences within a maize crop, due to horizontal inhomogeneity from natural variation, between half-hour averages (in ${ }^{\circ} \mathrm{C}$ ). Values are given for each height at which temperatures were measured (Table 2) and are maxima from 42 profiles over four complete measuring days.

\begin{tabular}{llllll}
\hline Height $(\mathrm{m})$ & $\begin{array}{l}\text { Temp. diff. } \\
\left({ }^{\circ} \mathrm{C}\right)\end{array}$ & Height $(\mathrm{m})$ & $\begin{array}{l}\text { Temp. diff. } \\
\left({ }^{\circ} \mathrm{C}\right)\end{array}$ & Height $(\mathrm{m})$ & $\begin{array}{l}\text { Temp. diff. } \\
\left({ }^{\circ} \mathrm{C}\right)\end{array}$ \\
4.50 & 0.2 & 2.10 & 0.5 & 0.60 & 0.7 \\
4.00 & 0.2 & 1.80 & 0.8 & 0.30 & 0.8 \\
3.50 & 0.4 & 1.50 & 0.4 & 0.10 & 0.9 \\
3.00 & 0.4 & 1.20 & 0.5 & 0.05 & 1.3 \\
2.50 & 0.5 & 0.90 & 0.5 & 0.02 & 1.5 \\
\hline
\end{tabular}


Table 5. Examples of temperatures (half-hour averages in ${ }^{\circ} \mathrm{C}$ ) measured at different places within a maize canopy near to the soil surface and averages (in the horizontal) of these measurements. (For the $30 \mathrm{~cm}$ level the average is of all 9 measurements at that height.) One may distinguish, be it not without many irregularities, certain warmer and colder profiles or places very near to the ground. Examples belong (from the first example downwards) to curves B, C, D, F, G, H respectively, from Fig. 3 and Fig. 4, and to masts $E^{\prime}, F^{\prime}$ and $D^{\prime}$.

\begin{tabular}{rlllll}
\hline Height $(\mathrm{cm})$ & Average & $\mathrm{E}^{\prime}$ & $\mathrm{E}^{\prime}$ & $\mathrm{F}^{\prime}$ & $\mathrm{D}^{\prime}$ \\
30 & & & & & \\
10 & 24.10 & 24.00 & 23.90 & 24.15 & 24.20 \\
5 & 23.65 & 23.55 & 23.15 & 24.10 & 23.85 \\
2 & 23.30 & 23.25 & 23.00 & 23.45 & 23.60 \\
& 23.10 & 22.60 & 22.90 & 23.20 & 23.60 \\
30 & & & & & \\
10 & 25.80 & 25.65 & 25.60 & 25.60 & 26.15 \\
5 & 25.15 & 25.00 & 24.85 & 25.10 & 25.70 \\
2 & 24.95 & 24.65 & 24.60 & 24.85 & 25.80 \\
& 24.50 & 24.10 & 24.30 & 24.40 & 25.20 \\
30 & 25.10 & 24.95 & 24.85 & 24.75 & 25.15 \\
10 & 24.25 & 24.15 & 24.10 & 24.20 & 24.60 \\
5 & 24.00 & 23.80 & 23.85 & 23.90 & 24.40 \\
2 & 23.55 & 23.40 & 23.50 & 23.30 & 24.05 \\
& & & & & \\
30 & 20.30 & 20.30 & 20.20 & 20.10 & 20.45 \\
10 & 20.20 & 20.45 & 19.95 & 19.95 & 20.45 \\
5 & 20.05 & 20.35 & 19.90 & 19.70 & 20.15 \\
2 & 19.95 & 19.85 & 20.10 & 19.45 & 20.45 \\
30 & 22.20 & 22.15 & 22.05 & 21.90 & 22.45 \\
10 & 21.95 & 21.95 & 21.70 & 21.80 & 22.35 \\
5 & 21.90 & 21.65 & 21.60 & 21.45 & 22.90 \\
2 & 21.40 & 21.20 & 21.35 & 20.85 & 22.15 \\
30 & & & & & \\
10 & 21.40 & 21.30 & 21.25 & 21.25 & 21.50 \\
5 & 21.10 & 21.05 & 20.90 & 20.95 & 21.50 \\
2 & 20.90 & 20.80 & 20.75 & 20.75 & 21.20 \\
\hline & 20.65 & 20.55 & 20.55 & 20.15 & 21.35 \\
\hline
\end{tabular}

from our results that this factor may increase the differences concerned but that the inhomogeneity of the soil surface regarding temperature and vapour pressure conditions may be concerned as the initiator of such differences.

On the average somewhat higher maximum differences in the horizontal were found, in the first $30 \mathrm{~cm}$, above the dry soil surface, which underlines again the key role played by the surface conditions in bringing into existence local microclimatic variations in the lowest canopy part. At $2 \mathrm{~cm}$ within the soil horizontal differences of 3 to $5{ }^{\circ} \mathrm{C}$ were measured in the middle of the day. At the surface these differences must be even higher, but a high temperature gradient has to exist over the boundary layer adhering to the soil surface, which explains that at $2 \mathrm{~cm}$ above the soil, which is already above that boundary layer (Stigter, 1972), the horizontal differences are already much lower. 
As to the different 'profiles' to be distinguished directly above the soil it may be assessed from Table 5 that at the $30 \mathrm{~cm}$ level these differences are already vanished for the biggest part. Above half a metre or so above the soil, maximum differences appear to be mostly at random and difficult to trace back or extrapolate regarding their sources and history. This is, at the other hand, a strong indication that differences as measured are highly representative of at least the $200 \mathrm{~m}^{2}$ concerned.

Regarding representativeness of single measurements of temperature within a maize crop our results indicate that they give rather a good idea in the higher parts of the crop and above the stand, if taken in representative areas. A maximum horizontal difference of $0.5^{\circ} \mathrm{C}$ as found in Table 4 does mean an estimated accuracy of $\pm 0.3{ }^{\circ} \mathrm{C}$ of a single arbitrary half hour average measurement with a thermometer of $\pm 0.05^{\circ} \mathrm{C}$ accuracy and without taking sampling errors into consideration. A maximum horizontal difference of $0.9{ }^{\circ} \mathrm{C}$ does mean an estimated accurary of $\pm 0.5^{\circ} \mathrm{C}$ for single temperature measurements averaged over half an hour, which by the way is valid from $10 \mathrm{~cm}$ upwards.

These errors are of course too high for half-hourly vertical flux calculations within and above the canopy, if these are allowed at all (Penman \& Long, 1960; Byrne and Rose, 1972). Estimations of the needed accuracies in that case are $0.1{ }^{\circ} \mathrm{C}$ (and 0.1 mbar) (Penman et al., 1967). For these purposes at least multi-point profiles or other sampling methods have to be used above and throughout the canopy. The number of measuring points to be averaged will certainly be higher in the lowest canopy regions very near to the soil surface if the same accuracy is necessary there.

\section{Acknowledgments}

The authors are much obliged to many members of their department for the indispensable cooperation in relation to preparation and performance of the measurements reported. This regards especially Messrs W. C. A. M. Hillen, A. E. Jansen, T. Jansen, Ing. B. Lammers, J. W. Vaags, B. Verhaaf and A. D. Welgraven. Regarding working out of the obtained data I am thankful to Ir J. G. Lengkeek and Messrs H. B. M. van der Ham, L. van der Neut and D. Verwaart. Sincere thanks are due to Dr Ir E. G. Kloosterman and his staff, from the University Agricultural Experiment Station in Flevoland, for their help in making it possible to do this field research in the maize stands at the station. Staff from the university computer centre kindly assisted in digesting the mass of data.

\section{References}

Begg, J. E., J. F. Bierhuizen, E. R. Lemon, D. K. Misra, R. O. Slayter \& W. R. Stern, 1964. Diurnal energy and water exchanges in bulrush millet in an area of high solar radiation. Agric. Met. 1: 294-312.

Birnie, J., P. Jansen \& C. J. Stigter. Multi-point temperature measuring equipment for crop environment, with some results on horizontal homogeneity in a maize crop. II. Equipment used. (In preparation.)

Bottemanne, F. A. \& Tj. Reitsma, 1973. Windprofielmetingen boven grasland; windprofielmetingen boven mais. Reports 73-1a and 73-1, Laboratory of Physics and Meteorology, Wageningen. (In Dutch.) 
Brown, K. W. \& W. Covey, 1966. The energy budget evaluation of the micrometeorological transfer processes within a corn field. Agric. Met. 3: 73-96.

Byrne, G. F., C. W. Rose, J. E. Begg, W. R. Torssell \& H. G. McPherson, 1971. Instrumentation for crop-environment measurement in a tropical savannah climate. Tech. Pap. CSIRO Div. Land Res. 32; 19 pp.

Byrne, G. F. \& C. W. Rose, 1972. On the determination of vertical fluxes in field crop studies. Agric. Met. 10: 13-17.

Dyer, A. J., 1968. The role of fetch in plant studies. In: F. E. Eckardt (Ed.), Functioning of terrestrial ecosystems at the primary production level. Nat. Resources Res. UNESCO, Paris, Ser. V: 493-498.

Fuchs, M. \& C. B. Tanner, 1965. Radiation shields for air temperature thermometers. J. appl. Met. 4: 544-547.

Geiger, R., 1961. Das Klima der bodennahen Luftschicht, 4. Auflage. Fr. Vieweg \& Sohn, Braunschweig, 646 pp.

Goudriaan, J. \& P. E. Waggoner, 1972. Simulating both aerial microclimate and soil temperature from observations above the foliar canopy. Neth. J. agric. Sci. 20: 104-124.

Goudriaan, J., 1977. Simulation of micrometeorological processes. Series 'Simulation Monographs', Pudoc, Wageningen (in press).

Idso, S. B. \& C. T. de Wit, 1970. Light relations in plant canopies. Appl. Optics 9 (1): 177-184.

Katić, P. \& S. Stanojević, 1964. Über Temperaturverhältnisse im Maisbestand im Laufe der Vegetationszeit. Angew. Met. 5 (1/2): 60-64.

Keulen, H. van \& W. Louwerse, 1974. Simulation for plant production. In: Agrometeorology of the wheat crop. Wld met. Orgn (WMO) No 396: 196-209.

Kreeb, K., 1974. Ökophysiologie der Pflanzen. Gustav Fischer Verlag, Stuttgart, 211 pp.

Landsberg, J. J., 1975. Temperature effects and plant response. Ch. 1.2.5. in: L. P. Smith (Ed.), Progress in plant biometeorology: the effect of weather and climate on plants, Vol. 1, period 1963-1974. Progress in Biometeorology Series, Division C. Swets and Zeitlinger, Amsterdam, $474 \mathrm{pp}$.

Lemon, E. R., D. W. Stewart, R. W. Shawcroft \& S. E. Jensen, 1973. Experiments in predicting evapotranspiration by simulation with a Soil-Plant-Atmosphere Model (SPAM). Ch. 4 in: R. R. Bruce et al. (Ed.), Field soil water regime, SSSA Special Publications Series 5. Madison, $212 \mathrm{pp}$.

Long, I. F., 1968. Instruments and techniques for measuring the microclimate of crops. In: R. M. Wadsworth (Ed.), The measurement of environmental factors in terrestrial ecology. Blackwell, Oxford, p. 1-32.

Meteorological Office, 1969. Handbook of meteorological instruments. I. Instruments for surface observations, 5th improved reprint. HMSO, London, $458 \mathrm{pp}$.

Milthorpe, F. L. \& J. Moorby, 1974. An introduction to crop physiology. Cambridge University Press, London, $202 \mathrm{pp}$.

Monteith, J. L., 1963. Gas exchange in plant communities. Ch. 7 In: L. T. Evans (Ed.), Environmental control of plant growth, Academic Press, New York, 449 pp.

Monteith, J. L., 1973. Principles of environmental physics. Edw. Arnold, London, $241 \mathrm{pp.}$

Owonubi, J. J., E. T. Kanemasu \& W. L. Powers, 1975. The microclimate of narrow- and wide-row sorghum with equal plant densities. Agric. Met. 15: 61-69.

Paltridge, G. W., 1970. A model of a growing pasture. Agric. Met. 7: 93-130.

Paltridge, G. W., 1972. Experiments on a mathematical model of a pasture. Agric. Met. 10: 39-54.

Paltridge, G. W., A. C. Dilley, J. R. Garratt, G. J. Pearman, W. Shepherd \& D. J. Conner, 1972. The Rutherglen experiment on Sherpa Wheat: environmental and biological data. Tech. Pap. CSIRO Div. Atmosph. Phys. 22; 41 pp. + data file.

Penman, H. L., D. E. Angus \& C. H. M. van Bavel, 1967. Microclimatic factors affecting evaporation and transpiration. Ch. 26 in: R. M. Hagan et al. (Ed.), Irrigation of agricultural lands. American Society of Agronomy, Madison, $1180 \mathrm{pp}$.

Penman, H. L. \& J. F. Long, 1960. Weather in wheat: an essay in micrometeorology. Q. J. Roy. met. Soc. 86: 16-50. 
Perrier, A., 1970. Méthodes et techniques de mesure des températures. In: Techniques d'étude des facteurs physiques de la biosphère. INRA, Paris, 543 pp.

Philip, J. R., 1964. Sources and transfer processes in the air layers occupied by vegetation. J. appl. Met. 3: 390-395.

Platt, R. B. \& J. F. Griffiths, 1964. Environmental measurement and interpretation. Van Nostrand-Reinhold Comp., New York, 235 pp.

Ramdas, L. A., 1946. The micro-climates of plant communities. Indian Ecol. 1 (1); 20 pp.

Rodskjer, N., 1975. A radiation compensated thermoelectric thermometer for use in crops. Arch. Met. Geoph. Biokl., Ser. B, 23: 111-126.

Schwerdtfeger, P., U. Radok, J. Bennet, B. van Meurs, I. Piggin, A. Usscher \& A. Wu, 1975. The micrometeorology of the plant environment. Ch. 1.1.1 in: L. P. Smith (Ed.), Progress in plant biometeorology: the effect of weather and climate on plants, Vol. 1, period 1963-1974. Progress in Biometeorology Series, Division C. Swets and Zeitlinger, Amsterdam, $474 \mathrm{pp}$.

Shawcroft, R. W., E. R. Lemon, L. H. Allen Jr., D. W. Stewart \& S. E. Jensen, 1974. The SoilPlant-Atmosphere Model and some of its predictions. Agric. Met. 14: 287-307.

Stigter, C. J., 1972. Leaf diffusion resistance to water vapour and its direct measurement. I. Introduction and review concerning relevant factors and methods. Meded. LandbHogesch. Wageningen 72-3: 1-47.

Stigter, C. J., 1974. The epidermal resistance to diffusion of water vapour: an improved measuring method and field results in Indian corn (Zea mays). Agric. Res. Rep. 831: 1-25. Pudoc, Wageningen.

Stigter, C. J. \& B. Lammers, 1974. Leaf diffusion resistance to water vapour and its direct measurement. III. Results regarding the improved diffusion porometer in growth rooms and fields of Indian corn (Zea mays). Meded. LandbHogesch. Wageningen 74-21: 1-76.

Stigter, C. J. \& A. D. Welgraven, 1976. An improved radiation protected differential thermocouple psychrometer for crop environment. Arch. Met. Geoph. Biokl., Ser. B, 24: 177-188.

Stigter, C. J., J. G. Lengkeek \& J. Kooijman, 1976. A simple worst case analysis for estimation of correct scanning rate in a micrometeorological experiment. Neth. J. agric. Sci. 24: 3-16.

Stigter, C. J., 1976. Water vapour pressure within a maize crop. Arch. Met. Geoph. Biokl., Ser. B, 24 (in press).

Stigter, C. J., J. Goudriaan, F. A. Bottemanne, J. Birnie, J. G. Lengkeek \& L. Sibma, 1977. Experimental evaluation of a crop climate simulation model for Indian corn (Zea mays). Agric. Met. 18 (in press).

Tamm, E. \& H. Funke, 1955. Pflanzenklimatische Temperaturmessung in einem Maisbestand. Z. Acker- u. PflBau 100: 199-210.

Tanner, C. B., 1963. Basic instrumentation and measurement for plant environment and micrometeorology. Soils Bull. Dep. Soil Sci. Univ. Wisc. No 6 (no cons. pag.).

Uchijima, Z., 1974. Micrometeorology of cultivated fields. In: Yoshiaki Mihara (Ed.), Agricultural meteorology of Japan. University of Tokyo Press, Tokyo, $215 \mathrm{pp}$.

Vaughan, H. C. \& C. Sakamoto, 1971. Measurement of ambient air temperature with aspirated and unaspirated thermocouples in the field. Iowa St. J. Sci. 46: 59-69.

Waggoner, P. E. \& W. E. Reifsnyder, 1968. Simulation of temperature, humidity and evaporation profiles in a leaf canopy. J. appl. Met. 7: 400-409.

Wit, C. T. de, 1970. Dynamic concepts in biology. In: I. Šetlík (Ed.), Prediction and measurement of photosynthetic productivity. Pudoc, Wageningen, $632 \mathrm{pp}$.

Wit, C. T. de \& F. W. T. Penning de Vries, 1977. Simulation of transpiration and growth of crops. Series 'Simulation Monographs'. Pudoc, Wageningen (in press). 